\title{
Intelligent Usage of Internal Combustion Engines in Hybrid Electric Vehicles
}

\author{
Teresa Donateo
}

Additional information is available at the end of the chapter

http://dx.doi.org/10.5772/48120

\section{Introduction}

Since early 1900s, gasoline and diesel internal combustion engines have represented the most successful automotive powering systems despite their low efficiency, their emissions issues and the increasing cost of fuel. Their main advantage over both gas engines and Battery Electric Vehicles (BEVs) is the very high energy density of liquid fuel that allows long driving ranges with small (and light-weight) storage tanks and safe and fast refueling processes. Moreover, gasoline and diesel fuels have an established infrastructure of distribution that is difficult and very expensive to replicate for other energy sources.

Environmental issues, energy crises, concerns regarding peaking oil consumption and the expected increase of number of cars in developing countries have eventually encouraged research into alternative energy sources. However, they are still unable to penetrate the market for several technological limitations.

The main drawback of BEVs resides in the batteries. They are still too expensive, too bulky and heavy (due to their low energy density). Moreover, they have an unsatisfactory life cycle and require long recharging times. Vehicles using fuel cell (FCV) a very clean fuel conversion system, have technologic drawback even higher. They add to the problems of a $\mathrm{BEV}$, the use of a very light gaseous fuel that has severe limitations in terms of producing process, storing system, safety and distribution infrastructure. Thus, they are not to be considered as a viable way for eco-mobility in the next future (German, 2003).

Hybrid electric vehicles are characterized by the presence of two different typologies of energy storage systems: usually a battery and a gasoline or diesel fuel tank. HEVs have no limitation of range with respect to conventional vehicle and use the existing distribution infrastructure. The main advantages of HEVs are: the flexibility in the choice of engine operating point that allows the engine to be run in its high efficiency region and the 
possibility of downsizing the ICE and so obtaining a higher average efficiency. Moreover, the engine can be turned off when the vehicle is arrested (e.g., at traffic lights) or the power request is very low (reduction of the idle losses).

PHEVs can be considered either as BEVs that can be run in hybrid mode when the state of the charge (SOC) of the batteries is low or as HEVs with batteries that can be recharged from the electricity grid. They are characterized by the use of much larger battery pack when compared with standard HEVs. The size of the battery influences the All Electric Range (AER), an important design parameters of PHEVs that is defined as the number of miles they vehicle can run in pure electric mode on the UDDS cycle. A vehicle is classified as PHEVXY if it has an AER of XY miles.

PHEVs require fewer fill-ups at the gas station than conventional cars and have the advantage, over HEV, of home recharging.

BEVs, HEVs, and PHEVs have also the capability of partially recovering energy from brakes by inverting the energy flow from batteries to wheels through the electric machine.

Simpson, 2006 presented a comparison of the costs (vehicle purchase costs and energy costs) and benefits (reduced petroleum consumption) of PHEVs relative to HEVs and conventional vehicles. On the basis of his model, Simpson found that PHEVs can reduce per-vehicle petroleum consumption. In particular, reductions higher than $45 \%$ in the petroleum consumption can be achieved using designs of PHEV20 or higher (i.e. vehicles containing enough useable energy stored in their battery to run more than $20 \mathrm{mi}(32 \mathrm{~km})$ on the UDDS cycle in electric mode according to the previous definition of AER).

The study of Simpson, 2006 underlined that from the economic point of view, the PHEVs can become a competitive technology is the cost of petroleum will continue to increase and the cost of the batteries will decrease.

Because of different characteristics of multiple energy sources, the fuel economy and the environmental impact of hybrid vehicles mainly depend on a proper power management strategy. The particular operating strategy employed in this kind of vehicles significantly influences the component attributes and the value of the PHEV technology (Gonder et al. 2007).

Generally speaking, the environmental impact of an ecologic vehicle has to be determined with a "well to wheel" (WTW) approach. From a "tank to wheel" (TTW) point of view, a $\mathrm{BEV}$, or a PHEV running in electric mode do not produce either pollutant or greenhouse gases while the emissions of pollutant and $\mathrm{CO}_{2}$ in the WTW processes depend on the primary source and the technology used to generate electric energy at the grid. The well-towheel $\mathrm{CO}_{2}$ emissions of a FCV can be equal to those of a diesel engine vehicle if it uses hydrogen produced from non-renewable energies sources (Guzzella and Sciaretta, 2007).

In a hybrid vehicle, the local emissions of $\mathrm{CO}_{2}$ and pollutant strongly depend on the management strategy used for the ICE that becomes the main issue in both HEVs and PHEVs. 


\section{Classification of hybrid vehicles}

Hybrid Electric Vehicles can be classified according to their architecture, the discharge/recharge mode of batteries and the level of hybridization.

As for architecture, HEV are called "parallel" when they use a gasoline or diesel engine mechanically coupled with an electric motor at the same shaft to satisfy the power request at the wheels. A parallel HEV can be run in five modes of operation (Guzzella et al, 2007): power assist (the electric motor give the supplementary torque to the shaft when the request is higher than engine available torque), battery recharging (a part of the engine power is used to recharge the batteries), electric mode (engine turned off), conventional vehicle (electric motor turned off) and regenerative braking.

In a "series" hybrid, the power request is entirely satisfied by the electric motor. Electric current to the motor is the algebraic sum of the current form/to the batteries and the current produced by an engine-driven generator. A series HEV can be run in four modes (the same of a parallel vehicle apart from conventional mode since the engine is not connected to the shaft).

Combined hybrid that can be run either in parallel and series mode have also been developed and introduced in the automotive market.

Traditionally, series HEVs have been neglected in scientific literature since they are less efficient than parallel HEVs and require more additional weight. Moreover, their energy management was considered trivial: a simple on-off engine control was considered sufficient. However, the increasing interest in plug-in vehicles has given new impulse to the research of advanced control strategies for series architectures.

There are two possible ways to regulate the energy management of hybrid vehicles with batteries. The first one (charge depleting mode, $\mathrm{CD}$ ) accepts the batteries to be completely discharged during the mission. In this mode, the battery SOC can increase or decrease in time but it tends to be reduced along the mission. This approach can be considered for plug-in vehicles only. The second one (charge sustaining mode, CS) tries to keep the battery always charge to not affect the vehicle autonomy. The SOC can increase or decrease in time but it tends tore main constant during the mission (for series and parallel HEVs, not possible for BEV).

A PHEVs is usually run in CD mode without using the engine until reaching a pre-assigned lower bound on the SOC, then a CS strategy is adopted. Another possibility is to discharge gradually the battery throughout the trip as in the so-called blended mode control (Tulpule et al., 2009).

This makes a PHEV more complex, more dependent on traffic and route information and more efficient than a standard series HEV.

Another classification of importance for hybrids is the degree of hybridization. MicroHybrids are quite similar to conventional vehicles, from that they differ for the presence of a slightly larger battery and a little more powerful electric motor that allow the engine to be 
turned off when the car is stopped at the cross-lights and then turned on again when the vehicles moves. This system, named Start\&Stop is nowadays adopted by several automotive companies in order to fulfill the Euro V standard. It does not require an increase of the voltage of the electric systems. The increase in cost and complexity is quite small like the potentiality to decrease fuel consumption. By further increasing the electric power and the voltage, it is possible to recover the braking energy ( $+5-10 \%$ in fuel economy, Chan, 2007). If the power of the electric motor increases, the internal combustion engine can be downsized and the electric motor is used to increase the pick power with the Power Assist logic. This is the case of mild hybrids (like Honda Civic and Honda Insight), that can increase fuel economy by $20-30 \%$ (Chan, 2007) with a similar increase of cost. Mild hybrids usually are not able to be run in all electric drive like Full Hybrids. Full hybrids can achieve a 40-50\% higher fuel economy than conventional car. (Chan, 2007) They work with very high tension in order to accept the largest electric power. They can be sub classified in Synergy Hybrids and Power Hybrids. The former are designed to maximize fuel economy (downsized engine) while the latter use the electric motor to increase the available torque (nodownsizing).

Finally, the term Range extender is used to define series hybrid vehicles where the small engine-alternator group is only used to recharge the battery when their SOC is too low.

\subsection{Designing and managing internal combustion engines for hybrid applications}

The role of the internal combustion engine in hybrid electric vehicles (HEVs) is quite different from conventional vehicle. The engine has no more to be designed to fulfill the performance (maximum speed, acceleration and climb) required for the vehicle but can be downsized, thus reducing fuel consumption and greenhouse emissions. Moreover, the internal combustion engine can be better managed in order to avoid low-efficiency and high-emission operations like idling, vehicle stops and strong accelerations.

The current approach to HEV design is to use internal combustion engines developed for conventional vehicles. From this point of view, the advantage of fuel economy of HEVs can be actually defeated by the higher complexity, weight and volume of the power-train. However, many of the electronic-controlled devices used in engine to increase their efficiency and reduce emissions at idle and low speed-low torque operating mode are completely useless in HEV applications. This means that simpler, lighter and less costly engine could be developed for hybrid applications.

It is well known that internal combustion engines have poor fuel economy and larger if they work at low temperature. This is particularly important in hybrid electric vehicles since they allow the engine to be turned off for long periods during which the engine temperature decreases. This can lead to higher cold-start emissions particularly due to the poor conversion efficiency of the after-treatment devices when the light off temperature is not reached. On the other hand, hybrid electric allow either engine or after-treatment devices or both devices to be controlled to reduce the warm-up period and improve their performances 
in a fully integrated approach (Bayar et al., 2010). In HEV, the engine is cranked to higher speed than conventional vehicles and this makes the combustion condition during startup process quite different. $\mathrm{Yu}$ et al., 2006, investigated the effect of cranking speed on the start/stop operation of a gasoline engine for hybrid applications. Once again, fuel economy and emission during the engine start process depend on the control strategy used for the engine and the motor.

In order to reduce the warm-up period of the engine Lee et al., 2011 considered the recovering of exhaust gas heat exchanging system with coolant and gear box oil simultaneously. Accordingly, they developed an exhaust heat recovery device, which performs integral heat exchange of the exhaust gas heat of engine to increase the temperature of the coolant and the gear box oil, thereby reducing friction loss and improving fuel economy.

\subsection{Approaches to the supervisory control models}

The capability of a HEV in reducing fuel consumption and pollutant emissions strongly depends on the supervisory control strategy and the specific driving conditions. In fact, in hybrid electric vehicles a supervisor control system defines in each time the power split between the fuel conversion system (engine/alternator or fuel cell) and the electric storage systems (batteries and/or super capacitors) in order to minimize fuel consumption, sustain battery charge and reduce polluting emissions. Note that these goals are competitive and the performance of the HEV strongly depends on which goal it is given a higher importance. The optimization should be performed, ideally, over the entire life cycle of the vehicle even if a much shorter time interval (from a small number of minutes to few hours) is usually taken into account.

Several approaches for the optimization of energy management of a HEV have been presented in literature (Serrao, 2009). They can be classified in four categories: numerical optimization, analytical optimal control theory, instantaneous optimization and heuristic control techniques.

Heuristic control techniques are based on a set of rules that generate control action (i.e., the power to be delivered from the two energy sources) according to the value of some vehicle parameters like speed, acceleration, battery SOC, etc. These methods easy to implement in vehicles but they do not guarantee the minimization of either fuel consumption or emissions and the achievement of charge sustaining at the end of the mission.

Numerical optimization usually applies dynamic programming to optimize the vehicle behavior with the unrealistic assumption of perfect knowledge of the vehicle driving conditions (Lin et al, 2003).

An alternative to dynamic program is the application of the Pontrayagin's principle. This approach assumes that the power train can be described with simple analytical functions. Thus, it is often a too simplified approach and it also requires the knowledge of the driving cycle to be applied (Anatone et al. 2005, Serrao et al. 2008). 
In the instantaneous optimization approach, the global minimization problem is implemented and solved as a sequence of local optimization problems. The best known of these strategies is the Equivalent Consumption Minimization Strategy for chargedsustaining vehicles. The ECMS tries to minimize the equivalent fuel consumption that is calculated as the sum, in a time interval $\Delta t$, of the actual engine fuel consumption and the fuel equivalent of the electric energy stored in/extracted from the battery in the time interval $\Delta t$. Since battery is only used as an energy buffer, its energy is produced ultimately by the fuel that the engine has consumed/saved in the past (or will consume in the future). The main drawback of the approach is that it requires the definition of equivalent factors in the conversion of fuel energy to electrical energy and vice versa (Guzzella and Sciarretta, 2007).

Recently, Millo et al. 2011 extended the ECMS technique to include engine emissions. In particular, they correlated the use of the battery with equivalent NOx emissions and compared the results of the fuel consumption-oriented optimization and the NOx optimization in terms of State of Charge history, engine operating points, etc. with respect to several standard driving cycles.

The usage of standard driving cycles in the optimization of the control strategies is a common way to obtain sub-optimal controller that, however, can give poor results in the real driving conditions.

\subsection{Prediction of vehicle driving patterns}

As explained before, the possibility of estimating the future driving profile (speed and related power demand) is a key issue in the development of hybrid vehicles. In fact, the supervisory controller of a HEV could use the future speed profile to optimize the power split in a future time window in order to minimize fuel consumption, pollutant emission, battery usage and so on. Moreover, the information about future can be used to activate the electric warming of engine and after-treatment devices. In this way they will be at the right temperature when the engine will be turned on and the exhaust gas flow will enter the aftertreatment device.

In literature, a number of "auto-adaptive" techniques which try to predict future driving conditions based on the past ones have been defined A possible approach is to predict the future driving conditions based on the past behavior of the vehicle (Sciarretta et al, 2004) relying on the assumption that similar operating conditions will exist. But the future driving profile also depends on the instantaneous decisions which the driver will take to respond to the physical environment (driving patterns). Moreover, recent studies have shown that driver style, road type and traffic congestion levels impact significantly on fuel consumption and emissions (Ericson, 2000, Ericson, 2001). For these reasons, the control strategies proposed in some schemes (Won et al, 2005) incorporate the knowledge of the driving environment.

In the case of series HEV, the knowledge of the driving conditions have been found in literature to be less important than in the case of parallel hybrids (Barsali et al,. 2004). 
In the case of plug-in hybrid electric vehicles, the control is more complex, strongly depending of the initial value of SOC and on the mission length, particularly if Blended Mode control methods are used. In fact, if the total trip was known, the best results would be obtained if the SOC would reach the lower value at the end of the trip (Karbowski et al. 2006). Gong et al. 2007, developed an Intelligent Transportation System that uses GPS information and historical traffic data do define the driving patterns to be used in the optimization. Donateo et al. 2011, have estimate numerically that the knowledge of the driving cycle in a future time window of $60 \mathrm{~s}$ can improve fuel consumption in a series PHEV with Blended Mode control by $20 \%$.

\section{ICT and sustainable mobility}

\subsection{Intelligent vehicle technologies}

According to Gusikhin et al. 2008, a vehicle can be defined as intelligent if it is able to sense its own status and that of the environment, to communicate with the environment and to plan and execute appropriate maneuvers. The first application of intelligent vehicle systems has been the increase of safety by providing driver assistance in critical moments. A combination of on-board cameras, radars, lidars, digital maps, communication from other vehicles or highway systems are used to perform lane departure warning, adaptive cruise control, parallel parking assistants, crash warning, automated crash avoidance, intelligent parking systems.

Markel et al. 2008 studied the effect of integration between an electrified vehicle fleet and the electric grid in order to increase the amount of renewable energy used to power the electric vehicles by optimizing the timing and the power of the charging processes during the day. Different communication protocols have been considered and compared by Markel et al. Intelligent Transport Systems like traffic management can have a direct effect on the emissions of $\mathrm{CO}_{2}$ produced by the automotive floats (Dimitrakopoulos, 2011). According to Janota et al. 2010, Intelligent Transportation Systems can reduce consumption and emissions by acting on the vehicle (by monitoring and controlling the engine), on the infrastructure (reduction of number/duration of congestions and stoppage, optimization of intersection, cooperative systems to avoid congestions) and on the driver (planning of ecologic routes based on real-time information, support to driver for economic drive).

Recently, Information and Communication Technologies (ICT) techniques have been proposed for gathering information about the vehicle routes and road conditions that could allow the evaluation of the future power request of the vehicle over a large time window. ICT techniques can be used to estimate the future driving profile, suggest low consumption behaviors to the driver, propose alternative route, communicate the position and the status of electric recharging stations, etc. (Sciarretta et al, 2004).

Schuricht et al. 2010 analyzed two active energy management measures. The first one, uses advanced traffic light, and communication systems to support the driver during intersection approaching. The second one explores the uses of information and sensor sources from the traffic telematics for the predictive online optimal control of hybrid vehicles. 


\subsection{The CAR approach}

The role of Intelligent Transport Systems in the improvement of PHEV performance and spreading of vehicles electrification is a research issue at the Center for Automotive Research at the Ohio State University. Starting from the awareness that traffic, weather and road conditions will be available in the next future through vehicle-to-vehicle and vehicleto-infrastructure communications, the researchers at CAR emphasize the possibility this information in order to adapt the tuning of the energy management controller in HEVs, predicting the future driving profile, signaling the availability of recharge stations, predicting the route and generating statistical information for modifying pre-stored maps.

In the paper of Tulpule et al. 2011, the authors concentrated on the impact of the available data on the energy management in order to identify the most important factors on the actual fuel consumption of a PHEV. The factors analyzed in the investigation, named "Impact Factors", derive from both weather information (temperature and humidity) and traffic information (status of traffic lights, presence of pedestrian, road events in intra-city highway and inter-city highway). Their importance on the performance of the ECMS strategy were evaluated on the basis of a large amount of data acquired on a Toyota Prius converted to plug-in mode. The plug-in Prius has been run for a total of 60,000 miles in the campus area of the Ohio State University and several parameters like GPS information, temperature, fuel consumption, battery SOC, etc. were collected along with time and date.

To study the effect of the driving patterns, Gong et al. 2011 used a statistic approach to analyze real world profiles and derive information about average speed, speed limits, segment length, etc. These data were used to build a series of reference driving cycles by using the Markov chain modeling. The results of the investigation showed that the driving patterns have a relevant effect on the performance of a plug-in HEV and that the statistic values of acceleration have the largest impact of the tuning of the ECMS strategy.

\subsection{The CREA approach}

The CREA idea of intelligent hybrid vehicle includes the possibility of sensing the traffic environment in which it moves to predict the future driving conditions (Ciccarese et al. 2010). In particular, the vehicle is assumed to receive information from GPS, on-board sensors and vehicular communications. The scheme of the intelligent HEV according to the CREA research center is shown in Figure 1.

This information can be used on-board to perform a simulation of the traffic in a pre-set time window in order to predict the power request pattern in the next future and execute on-line optimization of the energy management over the predicted power pattern. The main difference with the CAR approach is that the vehicle is assumed to be able to compute onboard a simulation of the traffic conditions by using a microscopic road traffic simulation to derive its own future power request profile and optimize fuel consumption, battery usage, emissions levels, etc. This approach requires a relevant on-board computational capability that we believe could be available in the next future for other applications like safety, 
entertainments and so on. Alternatively, the simulation of the traffic patterns and the calculation of the speed profiles of the vehicles in a particular urban zone could be performed by a central computational unit that could send the results to the vehicles circulating in that zone.

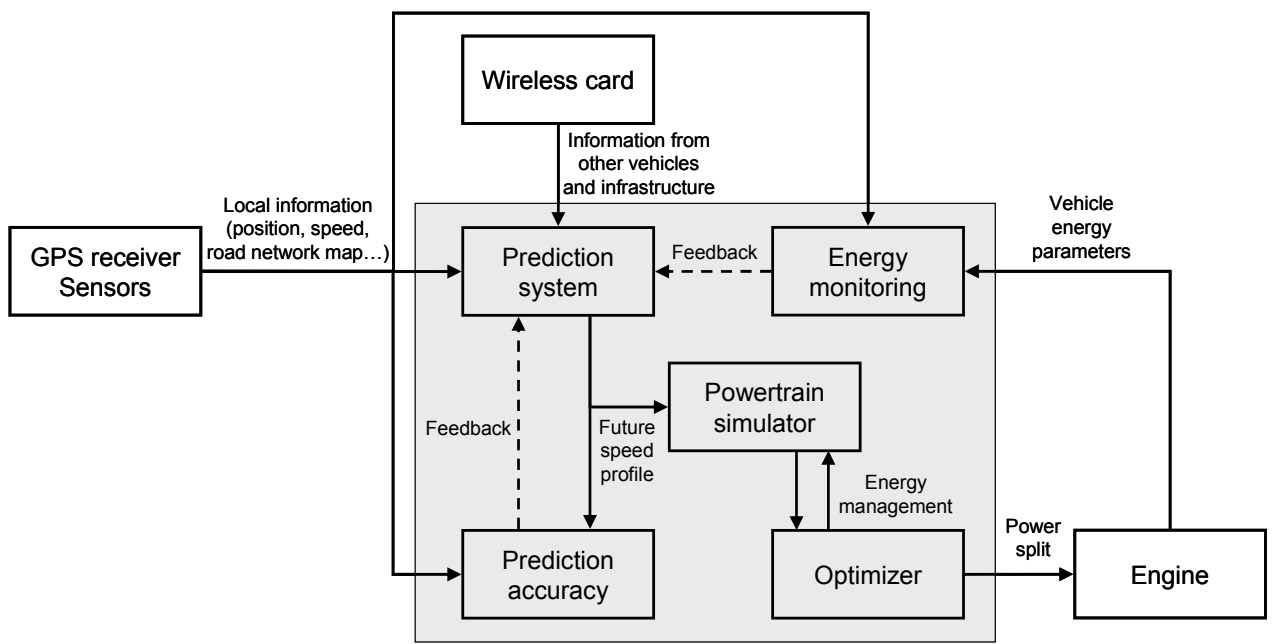

Figure 1. An intelligent hybrid vehicle according to the CREA approach

The gray area in Figure 1 represents the tools to be implemented on board. They include the prediction system, which is used to estimate the future speed profile of the vehicle, a power train simulator, which evaluates the evolution of fuel consumption and battery SOC during the prediction interval, and an optimizer, which is used to optimize the parameters of the control strategy.

\subsubsection{The prediction block}

This block gathers status messages that surrounding vehicles and/or the infrastructure broadcast. Messages transmitted by a vehicle carry status information, such as position, speed, acceleration, etc., and, optionally, some information related to its route. Messages generated by the infrastructure, instead, carry the current status and the timing of traffic lights. Besides the status information received through vehicular communications, the system gathers the status information on the "predicting vehicle" locally obtained by a GPS receiver and/or on-board sensors and also retrieves the data on road network from the digital maps used by the GPS navigation device.

The information gathered is exploited to take, at regular intervals, a snapshot of the traffic scenario in a given area. Each snapshot is the input to a run of module which simulates the traffic dynamics over a certain time interval, whose duration is at most equal to the prediction horizon. In Ciccarese et al. 2010, a modified version of SUMO software has been considered as on-board simulator. 
SUMO (Simulation of Urban MObility) is an open source microscopic road traffic simulator. The input parameters of SUMO consist of the road network, the characteristics of each vehicle, the path (route) that each vehicle follows and the timing of traffic lights.

Vehicles with the same characteristics are grouped in classes and, for each class, a set of mechanical specifications is provided maximum speed, acceleration and deceleration., vehicle length, mass, friction coefficients, etc.

The road network is represented by an oriented graph, where nodes correspond to intersections and arcs to one-way lanes. For each lane, the maximum speed, the slope and the classes of vehicles which are allowed to go along it have to be also specified. The route of a vehicle consists of a list of consecutive arcs in the graph.

Using the input data, SUMO generates a mobility trace for all vehicles according to a CarFollowing model (Wang et al. 2001): each vehicle tries to hold its speed close to the maximum one allowed for the current lane and decelerates if it is approaching either to an intersection or to another vehicle on the same lane; in the latter case, its speed is adapted to that of the vehicle which moves ahead of it.

The accuracy of the proposed prediction method has been tested experimentally (Ciccarese et al. 2012) in a augmented reality environment to simulate the presence in the Ecotecke campus of a certain number of vehicles able to communicate with the target vehicle. The experimental campaign showed that the inaccuracy of the prediction method is below $4 \mathrm{~km} / \mathrm{h}$. In Figure 2, a comparison is shown between the predicted and the actual speed profile of the target vehicle in a time window of 100s. More details about the experimental campaign can be found in Ciccarese et al. 2012.

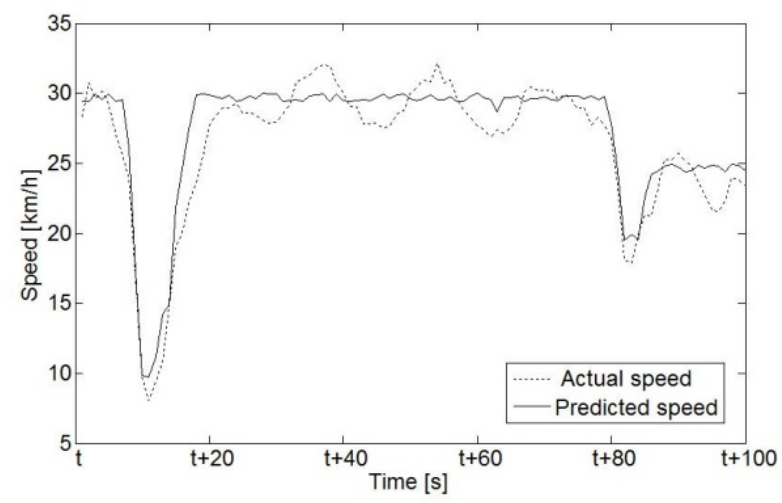

Figure 2. Example of speed profiles obtained by the experimental environment

\subsubsection{The power-train simulator}

The Power train simulator block implements a model of the power-train. The block processes the output of the prediction system and calculates the related power demand of 
the predicting vehicle by considering aerodynamic force, inertial contribution, rolling force and grade force. Information from on board sensors (ambient temperature, asphalt conditions, tires pressure and temperature) can be used to correct the predicted load. Then, the block simulates the energy flows according to the selected energy management strategy (described above) and evaluates the evolution of fuel consumption and battery SOC during the prediction interval.

Two different paradigms are usually considered to simulate a hybrid vehicle (Guzzella and Sciaretta, 2007). In the backward paradigm, the velocity of the vehicle is an input. According to the vehicle specification and speed values, the power request at the wheel is calculated. By means of static maps, the energy consumption of both engine and batteries is calculated according to the selected energy management strategy. If the power-train is not able to meet the cycle requirements, the acceleration is reduced and the vehicle diverges from the driving cycle.

In a forward or dynamic model, the power requested by the driver through the acceleration and braking pedals is used as input to evaluate the acceleration and the vehicle speed. This kind of model is used for the development of the control systems, while the backward method is best suited for analysis and evaluation of the energy and power flow in the vehicle driveline. Thus, a backward model is considered in the proposed scheme.

If the driving cycle is predicted with a traffic model that takes into account the actual acceleration and deceleration capability of the power-train, it is not necessary to check if the vehicle is able to follow the prescribed driving cycle.

\subsubsection{The energy management system}

This block implements the supervisor control system which defines, at each time, the power split between the fuel conversion system (engine/alternator in a series HEV) and the electric storage systems (generally batteries) with the constraints that the sum of the power extracted from each energy source must be equal to the total power requested at the wheels.

\subsubsection{The optimizer}

The role of the optimizer block is to adapt the parameters of the actual control strategy to the future driving conditions. This block can be implemented either as a on-line optimizer or as a memory device for loading optimized maps (Donateo et al. 2011).

\subsubsection{Monitoring blocks}

The system also includes a block, named Energy monitoring, which monitors the energy parameters of the vehicle (engine efficiency, level of gasoline in the tank, battery SOC, etc.) and evaluates the effectiveness in optimizing the energy management. This evaluation is carried out at regular intervals of duration equal to the prediction horizon. 
Another block, named Prediction accuracy, evaluates the prediction error (based on a comparison between the actual speed profile evaluated by GPS and that estimated by the prediction system). The output of the Prediction accuracy block could be used to trigger a new prediction run.

\section{A test case: ITAN500}

In order to evaluate the effectiveness of the CREA approach in reducing fuel consumption of a plug-in HEV, a numerical investigation has been performed with respect to ITAN500.. ITAN500 a four-wheel vehicle prototype with a size comparable with that of a large scooter. ITAN500 can be classified as PHEV40 because its all-electric range is 40 miles on the UDDS cycle.

The vehicle was designed to reach a maximum speed of $90 \mathrm{~km} / \mathrm{h}$ in hybrid configuration with a mass of about $800 \mathrm{~kg}$. By taking into account the overall transmission ratio $(1 / 3.46)$ the DC motor was selected in order to generate a torque of about $27 \mathrm{Nm}$ at the speed of 3560 $\mathrm{rpm}$. A set of six lead acid batteries in series are used to produce the nominal voltage of $72 \mathrm{~V}$ required to feed the electric motor. The choice of lead acid batteries was due to the need of reducing the vehicle cost. However, other kinds of batteries are currently under consideration.

A small gasoline engine with a maximum power of $9.9 \mathrm{~kW}$ at $3600 \mathrm{rpm}$ is used to extend the range of the vehicle. More details on the power-train (shown in Figure 3) can be found in a previous publication (Donateo et al. 2012).

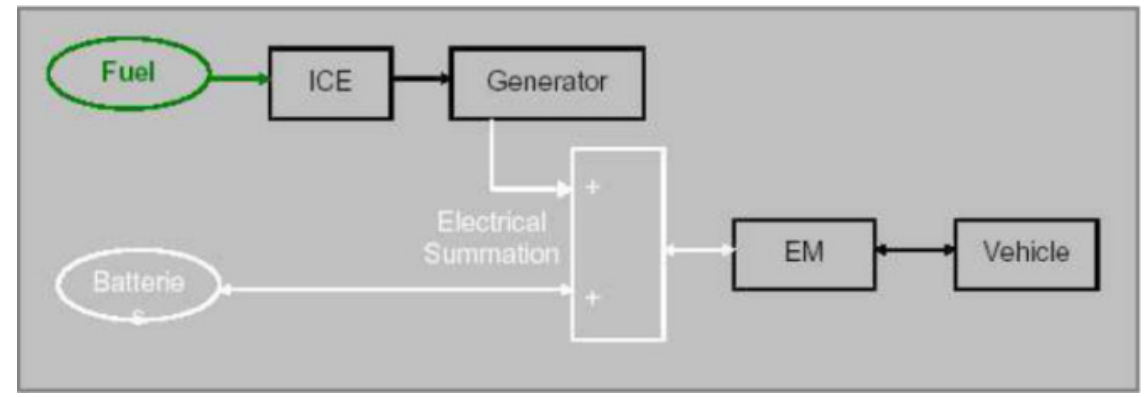

Figure 3. Scheme of the ITAN500 power-train

\subsection{The VPR power-train simulator}

VPR (Vehicle Power Request) is a backward model that uses quasi-static maps for the main power-train components (thermal engine, motor and batteries) to predict their efficiency according to the requested values of torque and speed.

The main outputs of the VPR model are the evolution of fuel consumption and battery SOC along the driving cycle. Starting from the velocity speed and grade traces, the vehicle power request is calculated by considering aerodynamic force, grade force, inertial contribution 
and rolling force. An example of vehicle power request trace is shown in Figure 4 together with other VPR output.

Note that during deceleration the power request is negative which means that the braking energy can be recovered and stored in the batteries. In the example shown in Figure 4, engine is turned on only in a small fraction of the vehicle missions, around 500s from the start of the cycle.
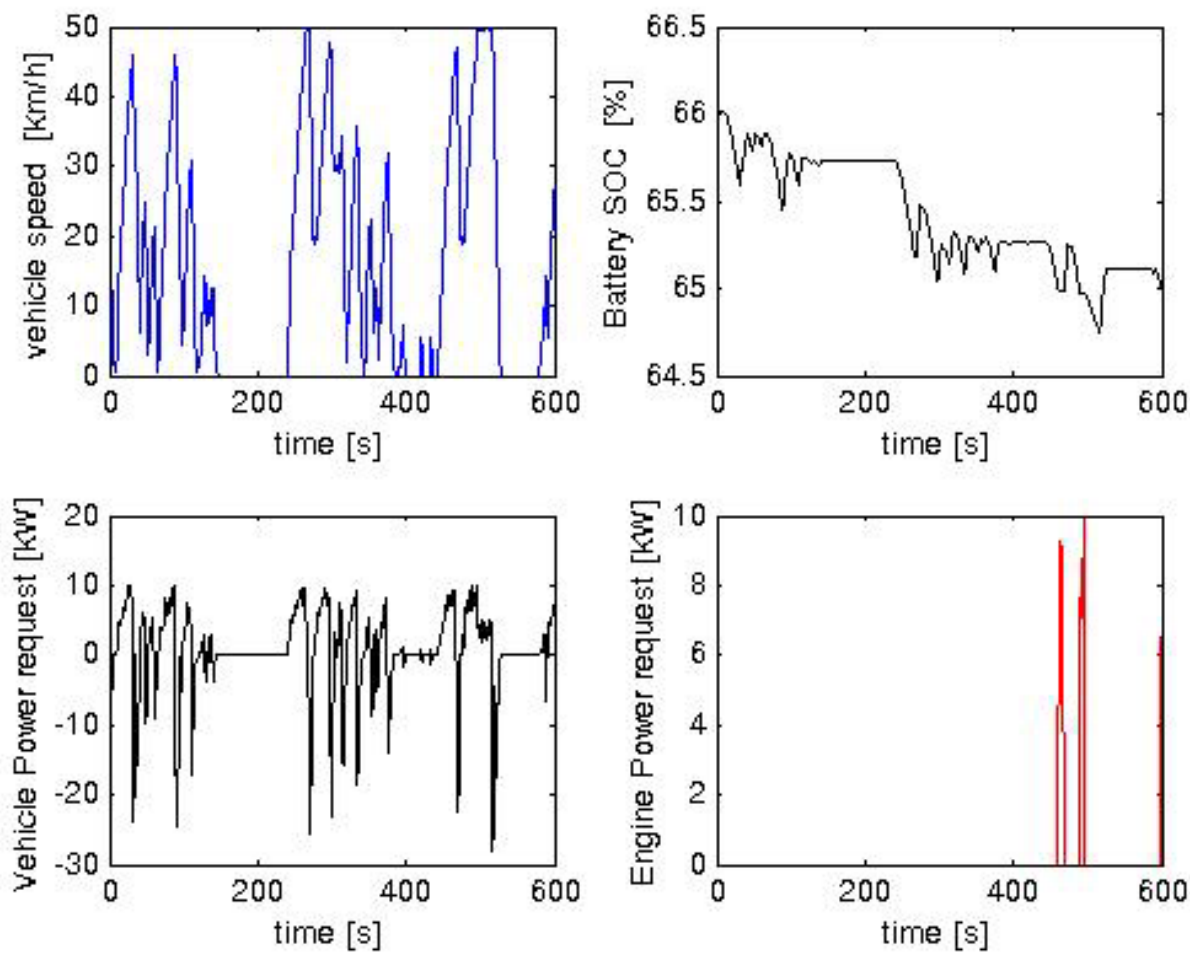

Figure 4. Example of VPR results

The efficiency of the electric motor according to torque and speed has been evaluated experimentally on an inertial test bench (Donateo et al. 2011).

Since the engine is run at the constant speed of $3000 \mathrm{rpm}$, its efficiency is considered as function of torque only. Literature data have been used to derive the maps of Figure 5.

The data of Figure 5 refers to a fully-warmed case, i.e. the temperature of the engine block is at the nominal temperature of $90^{\circ} \mathrm{C}$. However, engine efficiency is strongly dependent on its temperature; in particular it is very low at cold start. In the VPR model, the efficiency data of Figure 5 are corrected as proposed by Guzzella et Onder, 2004 by multiplying the fullwarmed engine efficiency by a correction factor whose dependence on temperature is shown in Figure 6. 


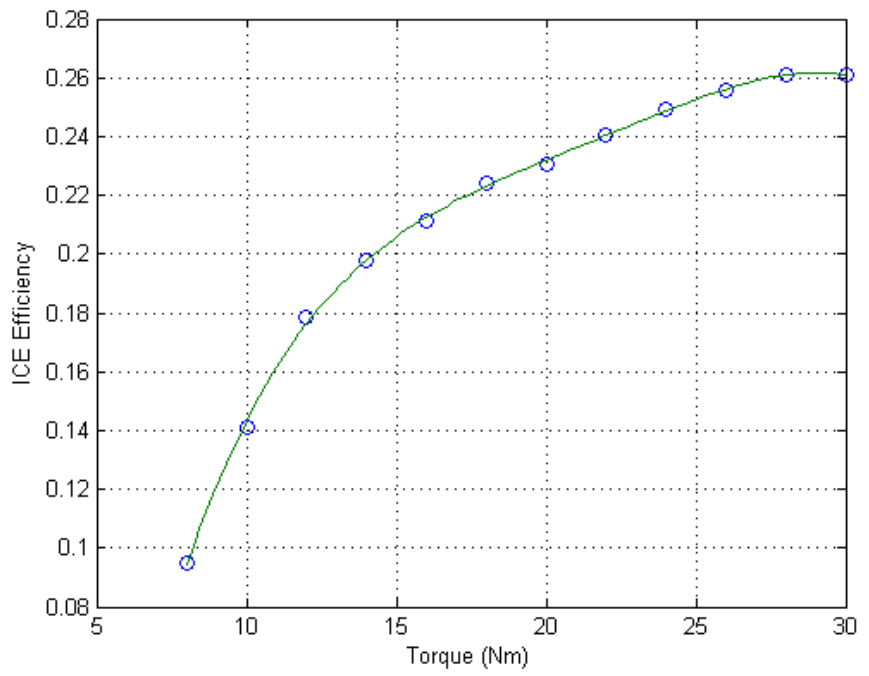

Figure 5. Fully-warmed engine efficiency versus torque at 3000rpm

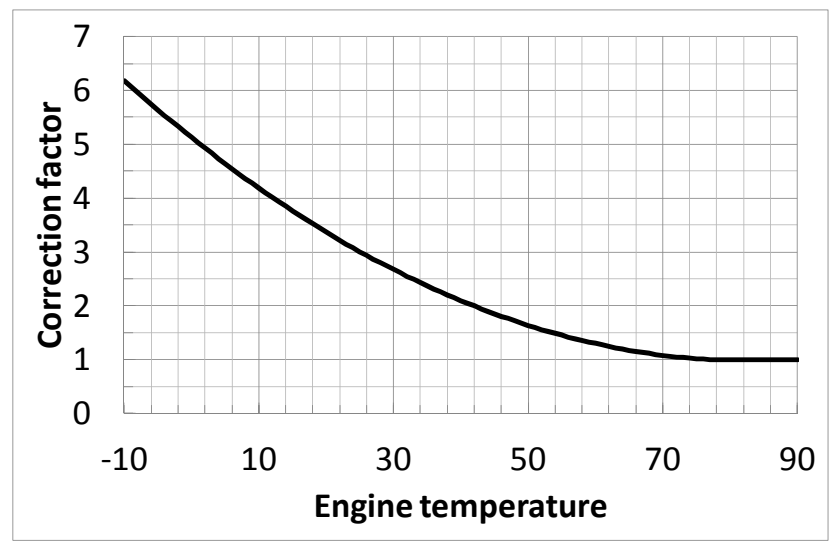

Figure 6. Correction factor for engine efficiency as a function of the block temperature

Note that if VPR is run on-board, the temperature of the engine block is a measured data while in the present investigation it has to be simulated. For this reason, a thermal model based on a zero-dimensional simulation of the engine has been proposed (Donateo et al. 2012). The thermal model is able to simulate the increase of temperature when the engine is on as a function of its actual torque. When the engine is off, its temperature decreases due to the heat transfer to the surrounding air. More details on the thermal model can be found in Donateo et al. 2012.

An example of temperature trace versus time obtained from VPR with the same input conditions of Figure 4 is shown in Figure 7. 




Figure 7. An example of temperature trace obtained with the thermal model of the engine

The overall electric efficiency between the chopper and the wheels is set constant and equal to 0.65 for the present investigation.

\subsection{The energy management strategy}

The energy management strategy developed for ITAN500 includes an initial Charge Depleting (CD) mode where the battery only is used until a threshold value of battery SOC is reached $\left(S O C_{C D}\right)$. Then, the vehicle can be run in three different modes.

In Mode 1, the power to the motor is supplied only by the generator/engine group.

Mode 2 uses only battery to supply power. Both engine and battery are used in the other modes. In particular, in mode 3 the engine is used both to charge battery and to supply power to the motor while in mode 4 the engine and the battery are used together to feed the motor.

According to the actual power to be supplied to the motor to move the wheels $\left(P_{\text {load }}\right)$ and instantaneous value of SOC, the power-train is operated in one of the Areas 1-11 of the Figure 8. In particular, mode 1 is preferred in the high power region except when the battery SOC is very high (Area 5). Mode 2 is mandatory in three cases: when the battery is fully recharged (Area 3), in braking (Area 1) and when the load power is very low (Area 2). Moreover, the use of mode 2 is preferred when the SOC is reasonably high and the load power relative low with respect to the engine nominal power (Areas 4 and 7), otherwise the use of engine is preferred (Areas 8). Area 6 and 9 correspond to the use of the engine to recharge the battery (mode 3 ). However, this is possible only when the sum of the load power and the power request to recharge the battery is lower than PICE,max. If not, mode 1 is used. 
Note that Areas 11 and 10 of Figure 8 were not taken into account because the power request is always lower than PICE,max for all the operating conditions considered in the present investigation.

The actual size of each area depends on the values of energy management parameters $S O C_{C D}, S O C_{\min }, k$ and $P_{I C E, \min }$ that influences the results in terms of fuel consumption and battery usage over a specific vehicle mission. The meaning of $S O C_{m i n}$, and PICE,min is quite straightforward while some explanation has to be given for $\mathrm{K}$. The $\mathrm{K}$ parameter was introduced to solve the dilemma between using mode 1 or mode 2 in Areas 7 and 8 since neither the engine nor the battery works at their best in that region. By using $\mathrm{K}$ it is possible to prefer the battery at relative low power and high SOC (area 8) and the engine otherwise .



Figure 8. Energy management strategy

\subsection{The optimizer}

The optimal combination of the parameters can be easily performed off-line with a general optimization algorithm like genetic algorithms (Paladini et al. 2007).

The role of the optimizer is to find the optimal combination of parameters in Table 1 that define the size of the areas of Figure 8. For the optimization described in this paragraph, the minimum and maximum values and the steps of variation of the design variables reported in Table 1 were considered.

\begin{tabular}{|l|l|l|}
\hline Variable & Min & Max \\
\hline SOCCD (\%) & 60 & 80 \\
\hline SOCMIN (\%) & 20 & 60 \\
\hline K & 0 & 1 \\
\hline PICE,min [W] & 500 & 6200 \\
\hline
\end{tabular}

Table 1. Design variables for the optimization

In each case, the goal of the optimization was the reduction of the equivalent fuel consumption calculated in the following way: 


$$
\dot{m}_{t o t}=w_{F C} \dot{m}_{I C E}(\vartheta)+\dot{m}_{e q, B A T T}
$$

where:

$\dot{m}_{I C E}(\vartheta)$ is the effective fuel consumption function of engine temperature $\theta$;

$w_{F C}$ is the weight assigned to the level of fuel stored in the tank. It is set equal to 1 if the tank level is greater than $25 \%$ When the tank level is very low, this parameter is increased to prefer battery usage when the fuel level is low. In particular $w_{F C}$ is 1.2 for $10 \%<$ tank_level $<25 \%$ and 1.5 for tank level lower than $10 \%$.

Note that eq. (1) has been obtained by adapting the equivalent fuel consumption defined by Sciarretta et al. 2004 for a parallel HEV to the specific power-train of ITAN500.

The equivalent fuel consumption of the battery is obtained as follows:

$$
\dot{m}_{e q, B A T T}=\frac{\eta^{\gamma} \cdot P_{B A T T}}{Q_{L H V} \cdot \Delta t}
$$

where $\eta$ represents the average fuel consumption of the battery which is assumed to be constant and the same in charge and discharge in the present investigation.

When the battery is in charge, $P_{B A T T}$ represents the power that could be stored in the battery. Due to the battery efficiency $\eta$, the actual power stored in the battery (which define the


In discharge, $P_{B A T T}$ is the power requested from the battery is increased by $\eta(\gamma=-1)$.

To complete the description of eq. (3), $Q_{L H V}$ is the lower heating value of the fuel (in the present investigation gasoline is considered with $Q_{L H V}=44 \mathrm{MJ} / \mathrm{kg}$ while $\Delta t$ is the time step of the driving cycle $(\Delta t=1 \mathrm{~s})$.

The penalty function $f_{p}(S O C)$ takes into account the battery usage in the optimization process and has been defined according to Sciarretta et al. 2004.

\subsubsection{Driving cycles}

In the present investigation three kinds of driving cycles were taken into account for ITAN500. The first two are standard driving cycle adopted for the registration on new cars (NEDC and UDDS). Other numerical cycles were obtained with the help of SUMO. The ITAN500 has been simulated to move in the Ecotekne campus of the University of Salento for about 10000s (2.8h) together with other vehicles that, unlike ITAN500, can enter and exit the campus area. Different driving scenarios were taken into account by changing the number and the specification of the vehicles moving in the area.

The specification of the vehicles are used in the framework of SUMO to calculate the maximum values of acceleration/deceleration allowed to each vehicle according to the difference between the actual power request (depending on aerodynamics, rolling and inertia) and the maximum traction/braking power of the vehicle. Cycles obtained in this way 
were named as Trace A to Trace H. More details on the procedure used to obtain the numerical cycles can be found in Donateo et al. 2011.

Another cycle named $\mathrm{R}$ has been taken into account. This cycle is an actual driving cycle acquired with a GPS system on board of the vehicle ITAN500 when it is run in all electric range. The cycle has been assumed to be executed for 25 times $\left(R^{*} 25\right)$ in order to obtain results of fuel consumption and battery usage comparable with those of cycles A and B.

The specifications of the cycles taken into account in the investigation are reported in Table 2. Note that all the cycles taken into account in the present investigation refer to a zero grade condition.

\begin{tabular}{|l|l|l|l|l|}
\hline Cycle & Total time $[\mathrm{s}]$ & $\begin{array}{l}\text { Average } \\
\text { speed }[\mathrm{m} / \mathrm{s}]\end{array}$ & Max speed $[\mathrm{m} / \mathrm{s}]$ & $\begin{array}{l}\text { Min speed } \\
{[\mathrm{m} / \mathrm{s}]}\end{array}$ \\
\hline Cycle_NEDC & 1225 & 8.93 & 33.36 & 0 \\
\hline Cycle_UDDS & 1370 & 8.73 & 25.37 & 0 \\
\hline Cycle_1015 & 661 & 6.90 & 19.45 & 0 \\
\hline Cycle_HWFET & 766 & 21.56 & 26.80 & 0 \\
\hline Trace A & 10001 & 4.69 & 13.90 & 0 \\
\hline Trace B & 10801 & 6.88 & 13.90 & 0 \\
\hline Trace C & 9999 & 1.79 & 8.33 & 0 \\
\hline Trace D & 10001 & 2.00 & 8.33 & 0 \\
\hline Trace E & 10001 & 1.38 & 8.33 & 0 \\
\hline Trace F & 10001 & 1.08 & 8.33 & 0 \\
\hline Trace G & 10001 & 1.95 & 8.33 & 0 \\
\hline Trace H & 10001 & 1.47 & 8.33 & 0 \\
\hline Cycle R & 382 & 25.75 & 41.61 & 0.2 \\
\hline
\end{tabular}

Table 2. Specification of the driving cycle taken into account for the creation of the maps

\subsubsection{Full knowledge approach}

In this approach the driving cycle is assumed to be completely known and the parameters of Table 1 are optimized for each cycle of Table 2. The results of the application of this approach to cycles A, B, R, NEDC and UDDS are reported in Table 3.

\begin{tabular}{|l|l|l|l|l|l|l|l|l|}
\hline Cycle & $\begin{array}{l}\text { Duration } \\
{[\mathbf{s}]}\end{array}$ & $\begin{array}{l}\text { Equiv.fuel } \\
\text { cons. } \\
{[\mathbf{1} / \mathbf{1 0 0 k m}]}\end{array}$ & $\begin{array}{l}\mathbf{\Delta} \\
\text { SOC } \\
{[\mathbf{\%}]}\end{array}$ & $\begin{array}{l}\text { FC } \\
{[\mathbf{l}]}\end{array}$ & $\begin{array}{l}\text { SOCCD } \\
\mathbf{( \% )}\end{array}$ & $\begin{array}{l}\text { SOCMIN } \\
\mathbf{( \% )}\end{array}$ & $\mathbf{K}$ & $\begin{array}{l}\text { PICE,MIN } \\
{[\mathbf{k W}]}\end{array}$ \\
\hline \#A & 10000 & 2.78 & 24.8 & 1.02 & 65 & 44.4 & 0.9 & 3.2 \\
\hline \#B & 10800 & 3.1 & 24.7 & 1.96 & 77.9 & 50.1 & 0.6 & 2.6 \\
\hline \#R 25 & 9550 & 3.38 & 24.8 & 1.91 & 77.3 & 34.8 & 0.98 & 2.4 \\
\hline \#UDDS & 1370 & 1.66 & 18.7 & 0.08 & 60.6 & 37.6 & 0.97 & 6.1 \\
\hline \#NEDC & 1225 & 2.52 & 17 & 0.16 & 71.4 & 35.6 & 0.26 & 5.9 \\
\hline
\end{tabular}

Table 3. Results of the optimization in the case of full knowledge (initial SOC $45 \%$ ) 


\subsubsection{No-knowledge approach}

The driving cycle is assumed to be completely unknown. The parameter of the control strategy are optimized for the NEDC cycle and applied to the other cycles. The results are reported in Table 4.

\begin{tabular}{|l|l|l|l|l|l|l|l|l|}
\hline Cycle & $\begin{array}{l}\text { Duration } \\
{[\mathbf{s}]}\end{array}$ & $\begin{array}{l}\text { Equiv.fuel } \\
\text { cons. } \\
{[\mathbf{1} / \mathbf{1 0 0 k m}]}\end{array}$ & $\begin{array}{l}\boldsymbol{\Delta} \\
\text { SOC } \\
{[\%]}\end{array}$ & $\begin{array}{l}\text { FC } \\
{[\mathbf{l}]}\end{array}$ & $\begin{array}{l}\text { SOCCD } \\
\mathbf{( \% )}\end{array}$ & $\begin{array}{l}\text { SOCMIN } \\
(\mathbf{\%})\end{array}$ & K & $\begin{array}{l}\text { PICE,MIN } \\
{[\mathbf{k W}]}\end{array}$ \\
\hline \#A & 10000 & 3.47 & 25 & 1.29 & 71.4 & 35.6 & 0.26 & 5.9 \\
\hline \#B & 10800 & 3.85 & 25 & 2.38 & 71.4 & 35.6 & 0.26 & 5.9 \\
\hline \#R $\mathrm{R}^{* 25}$ & 9550 & 3.89 & 25 & 2.19 & 71.4 & 35.6 & 0.26 & 5.9 \\
\hline \#UDDS & 1370 & 1.67 & 18.7 & 0.08 & 71.4 & 35.6 & 0.26 & 5.9 \\
\hline \#NEDC & 1225 & 2.52 & 17 & 0.16 & 71.4 & 35.6 & 0.26 & 5.9 \\
\hline
\end{tabular}

Table 4. Results of the optimization in the case of no knowledge (initial SOC $45 \%$ )

\subsubsection{Prediction $\mathcal{E}$ maps supervisory control}

In order to reduce the on-board computational load required by the CREA approach, Donateo et al. 2011 proposed the use of maps that are optimized off-line with respect to reference driving conditions. They were obtained with the following procedure.

All cycles of Table 2 have been taken into account to generate one global driving cycle of 85208s (about 23 hours). Then, the VPR has been used to calculate the corresponding power request according to the specification of the vehicle and a global power request trace has been obtained. This power request trace has been divided into 1420 Mini Power Cycles (MPC) of $60 \mathrm{~s}$.

The 1420 MPCs have been distributed in 90 groups with the help of the K-Means clustering technique. For each group, a representative driving cycle, named Reference Mini Power Cycle has been identified and numbered.

Figure 9 shows, with different colors, five MPCs belonging to the same group. The bold blue line is the RMPC chosen with the clustering algorithm.

The off-line optimization has been performed for each of the 90 RMPCs, two levels of engine temperature (cold-hot), three levels of the initial state of charge, and three levels of the fuel tank. In this way 1620 optimized maps have been obtained. Each map contains the optimized values of $\mathrm{SOC}_{\mathrm{min}}, \mathrm{k}$ and PICE,min. for a particular combination of RMPC, engine temperature, initial state of charge and level of the fuel tank.

The maps could be used in an intelligent hybrid electric vehicle in the following way.

1. At any interval of 60 seconds, the predicted speed profile is obtained from the prediction block; 
2. The corresponding power request profile over $60 \mathrm{~s}$ is calculated according to the vehicle and road specification (es. grade) with VPR;

3. The power request profile is compared with each of the RMPCs and the most similar one in terms of root mean square error is found;

4. According to the measured values of engine temperature, fuel tank level and battery state of the charge, the corresponding map is loaded;

5. The optimized values of the energy management parameters of the selected map are applied over the next 60 s.

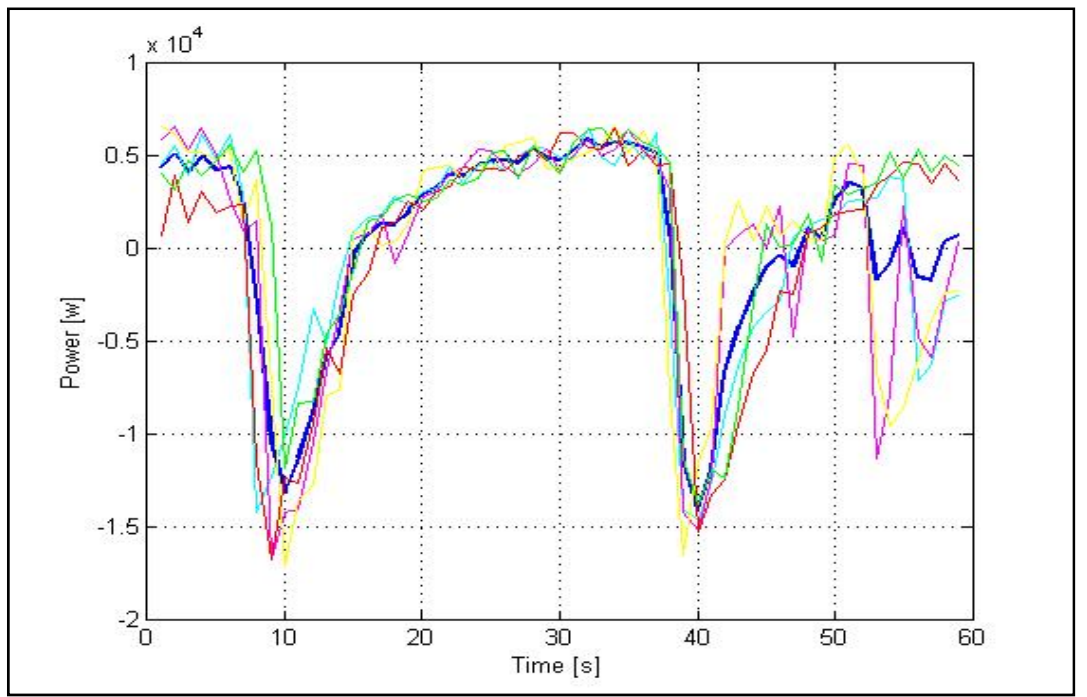

Figure 9. Example of RMPC

\subsection{Analysis of the prediction\&maps approach}

The proposed on board prediction-optimization tool has been evaluated numerically in the following way. The ITAN500 is simulated to execute one of the driving cycles of Table 2 with the assumption that they are know (by prediction) in blocks of 60s.

At any 60s, the power request versus time in the next time window of 60 s is evaluated with VPR and compared with each of the RMDCs to find the most similar one. Then, the instantaneous values of engine temperature, SOC and fuel levels are set as initial values and the corresponding optimized map is loaded. The thermal model of VPR is used to predict the profile of engine temperature along the mission. The values of the energy management parameters are used to evaluate the fuel consumption and battery usage in the next $60 \mathrm{~s}$ on the basis of the actual power request (not on the selected RMDC).

The results in terms of fuel consumption and battery usage obtained with this approach are reported in Table 5. 


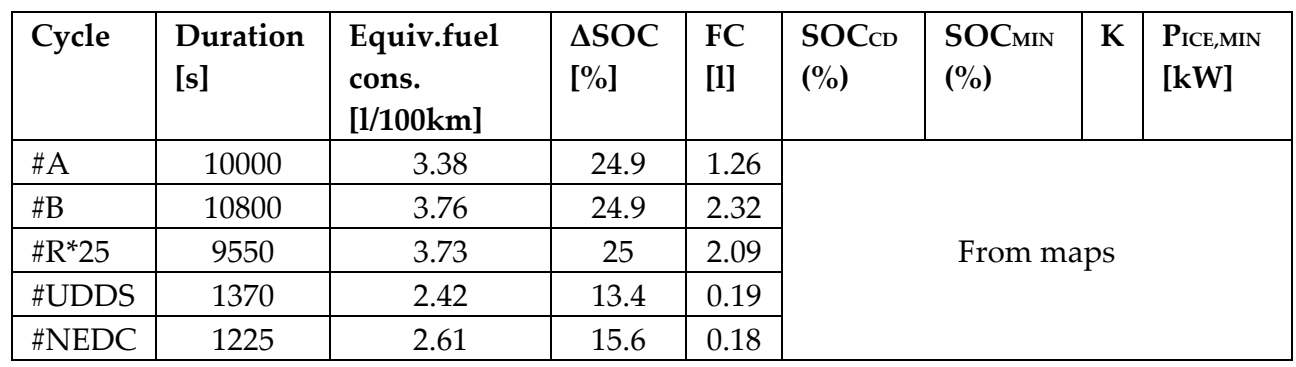

Table 5. Results of the simulation with the optimized maps (initial SOC 45\%)

\subsubsection{Percentage of mission with Controlled Battery Discharge (CBD\%)}

To compare the results of the three approaches, different metrics can be taken into account.

The first metric useful to compare the results of the three approaches can be derived by analyzing the typical SOC trace versus time in a plug-in hybrid electric vehicle. An example is shown in Figure 10 with respect to two different initial values of the battery SOC.

The traces of SOC show an initial zone where the results corresponding to full knowledge, predictionsmaps and no knowledge are perfectly overlapped and the SOC decreases monotonically (Electric Mode). Of course this region is particularly evident and relevant when the initial SOC is higher (75\%).

Then, there is a region in which the SOCs tends to decrease but can be kept locally constant or be increased thanks to the use of the engine (Plug-in Hybrid Mode). This region ends when the battery is fully discharged (SOC $=20 \%$ ). After this, the SOC remains globally constant for all cases (full knowledge, predictionEmaps and no knowledge) with small variation that are not visible in the scale used for the Figures (Discharged Battery Mode). Thus, the different results in terms of fuel consumption obtained with the three methods can be accounted for with the different duration of the EM, PHM and DBM zones.

In the EM region, the fuel consumption is zero but the SOC strongly decreases due to the extensive use of the battery. In the PHM mode, the battery is the main energy source and the engine is turned on (when its efficiency is high) to decrease the slope of the SOC trace. The DBM region is the worst in terms of fuel consumption because engine has to be run also in its low efficiency region since batteries are fully discharged. A plug-in HEV is run at its best when the DBM region (SOC=20\%) is reached exactly at the end of the mission and the EM region extends through as much of the mission possible. This is possible when the vehicle mission is entirely known (full knowledge case). The traces of Figure 10 show that the proposed method performs better than the no knowledge case since it allows to reduce the length of the DBM and to increase the PHM. As a consequence, the ICE is averagely run at high efficiency.

Thus, a useful metric to evaluate the performance of an energy management strategy for PHEV could be the percentage of the mission run in EM+DBM modes. This metric is named 
here CBD\% while in a previous investigation (Donateo et al. 2012) it was referred to as $\Delta$ mission.



Figure 10. Explanation of the meaning of $\mathrm{CBD} \%$ for Cycle $\mathrm{A}$

The value of the $\mathrm{CBD} \%$ has been calculated for each approach with reference to cycle $\mathrm{A}, \mathrm{B}$ and $R^{*} 25$ of Table 2 . $R^{*} 25$ means that cycle $R$ has been repeated 25 times to achieve a duration similar to that of cycle A and B.

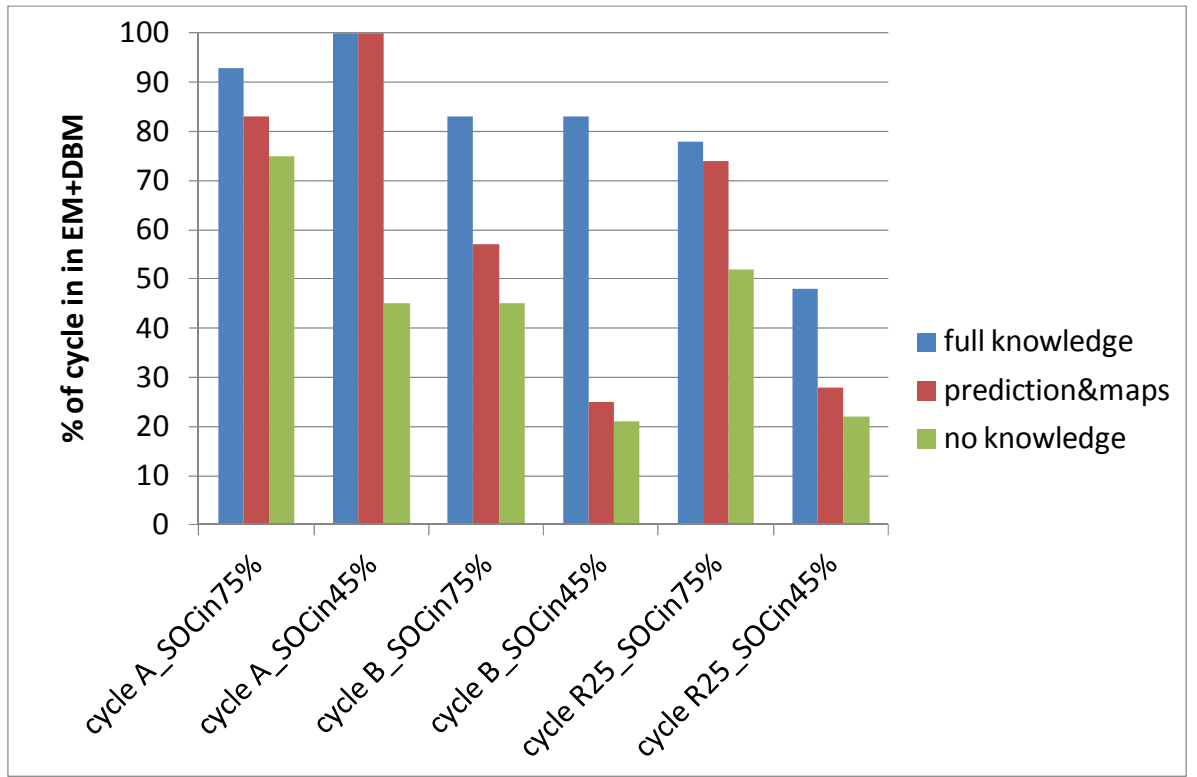

Figure 11. Values of CBD\% for cycles A, B and $\mathrm{R}^{*} 25$ with SOCin $=45 \%$ and $75 \%$ 
By analyzing the results of Figure 16 it is possible to notice that the performance of the proposed strategy is very close to that of full knowledge for cycle A (for both values of SOCin) and for cycle $\mathrm{R}$ with SOCin $=75 \%$. The values of $C B D \%$ are always slightly higher than in the no knowledge approach for the other cycles.

These results suggest that better performances could be obtained by increasing the duration of the prediction window used in the present investigation (60s) even if this could results in a worse accuracy of the prediction. Future development will be related to the optimization of the prediction horizon to increase the \% of the mission covered by EM+DBM.

\subsubsection{Percentage of mission with EngineON (engON\%)}

Another aspect to be taken into account in evaluating the performance of the proposed energy management strategy is the usage of the internal combustion engine in terms of percentage of mission during which the engine is turned ON (EngON\%).

The results are shown in Figure 12 with respect to cycles A and B to understand the results of Figure 11. Note that cycle B requires the engine to be turned on for a much higher percentage of the mission with respect to cycle A. This explains why this cycle is more critical in the optimization of metric CBD\%. Even if the predictionsmaps is not much successful in optimizing $\mathrm{CBD} \%$, it is able to strongly reduce the usage of the engine in both cycle $\mathrm{A}$ and $\mathrm{B}$.



Figure 12. Values of EngON\%for cycles A and B (SOCin=45\%)

\subsubsection{AEE (Average Engine Efficiency)}

The average efficiency of the engine (AEE) is another important aspect to be taken into account. The results of the comparison are reported in Figure 13.

Once again, the worst performance of the predictionsmaps method are obtained for cycle B. 




Figure 13. Values of AEE (SOCin=45\%)

\subsubsection{Well-to-wheel emissions of $\mathrm{CO}_{2}$}

The ultimate goal of advanced power-train technologies is to reduce the overall emissions of greenhouse gases. Thus, it could be interesting to evaluate the overall well-to.-wheel (WTW) emissions of $\mathrm{CO}_{2}$ produced with the different approaches considered in this investigation.

The complete combustion of 1 liter of gasoline produces $2.4 \mathrm{~kg}$ of $\mathrm{CO}_{2}$. Assuming a density of $700 \mathrm{~kg} / \mathrm{m} 3,1 \mathrm{~kg}$ of gasoline produces $3.42 \mathrm{~kg}$ of $\mathrm{CO}_{2}$ (tank to wheel emissions). Sullivan et al. 2004 consider a multiplying factor of 1.162 to pass from TTW to WTW emissions of $\mathrm{CO}_{2}$. Thus, a $\mathrm{kg}$ of gasoline can be assumed to produce $3.98 \mathrm{~kg}$ of $\mathrm{CO}_{2}$ (WTW). Using this conversion factor, the total $\mathrm{CO}_{2}$ produced along the cycles \#A, \#B and \#R25 has been calculated from the results in Table 3 (i.e. for the full knowledge case).

As for the electric emission, the TTW contribute is obviously zero while the well-to-tank (WTT) emissions depend on the energy mixing used to generate the electricity stored in the batteries. A report from the International Energy Agency, 2011 indicates for Italy an average emission of $0.386 \mathrm{~kg}$ of $\mathrm{CO}_{2}$ per $\mathrm{kWh}$ of electric energy. Using the data about the capacity of the batteries (equivalent $1.8 \mathrm{kWh}$ ) and the results in terms of SOC, it is possible to evaluate the total energy used for each cycle and for each approach. Thus, the electric WTT emission of $\mathrm{CO}_{2}$ can be easily calculated.

The calculated values of $\mathrm{CO}_{2}$ emissions from engine and batteries with the full-knowledge approach are reported in Table 6 . Note that the electric emissions are almost negligible with respect to the quantity of $\mathrm{CO}_{2}$ produced by the engine even if the engine is used only for a fraction of the mission. Moreover, they are quite the same for all cycles since the batteries are fully discharged in all cases.

The calculation of the total $\mathrm{CO}_{2}$ emissions has been repeated for the no-knowledge and prediction Emaps cases. The comparison is shown in Figure 14. 


\begin{tabular}{|l|l|l|l|l|l|}
\hline Cycle & $\begin{array}{l}\text { Usage of Electric } \\
\text { energy }\end{array}$ & $\begin{array}{l}\text { Fuel } \\
\text { consuption }\end{array}$ & $\begin{array}{l}\mathrm{CO}_{2} \text { from engine } \\
(\mathrm{WTW})\end{array}$ & $\begin{array}{l}\mathrm{CO}_{2} \text { from } \\
\text { Battery }(\mathrm{WTT})\end{array}$ & $\begin{array}{l}\text { total } \mathrm{CO}_{2} \\
(\mathrm{WTW})\end{array}$ \\
\hline & {$[\mathrm{kWh}]$} & {$[$ liters $]$} & {$[\mathrm{kg}]$} & {$[\mathrm{kg}]$} & {$[\mathrm{kg}]$} \\
\hline \#A & 24.8 & 1.02 & 2.92 & 0.172 & 3.09 \\
\hline \#B & 24.7 & 1.96 & 5.61 & 0.172 & 5.78 \\
\hline \# $\mathrm{R}^{* 25}$ & 24.8 & 1.91 & 5.47 & 0.172 & 5.64 \\
\hline
\end{tabular}

Table 6. Well to wheel emissions of $\mathrm{CO}_{2}$ in the case of full knowledge

The results of Figure 14 reveal that complete information about the future driving mission could help to significantly reduce the overall emission of $\mathrm{CO}_{2}$ from a plug-in series HEV. The estimated reduction ranges from $12 \%$ for cycle \# $R^{*} 25$ to $20 \%$ for cycle \#A.

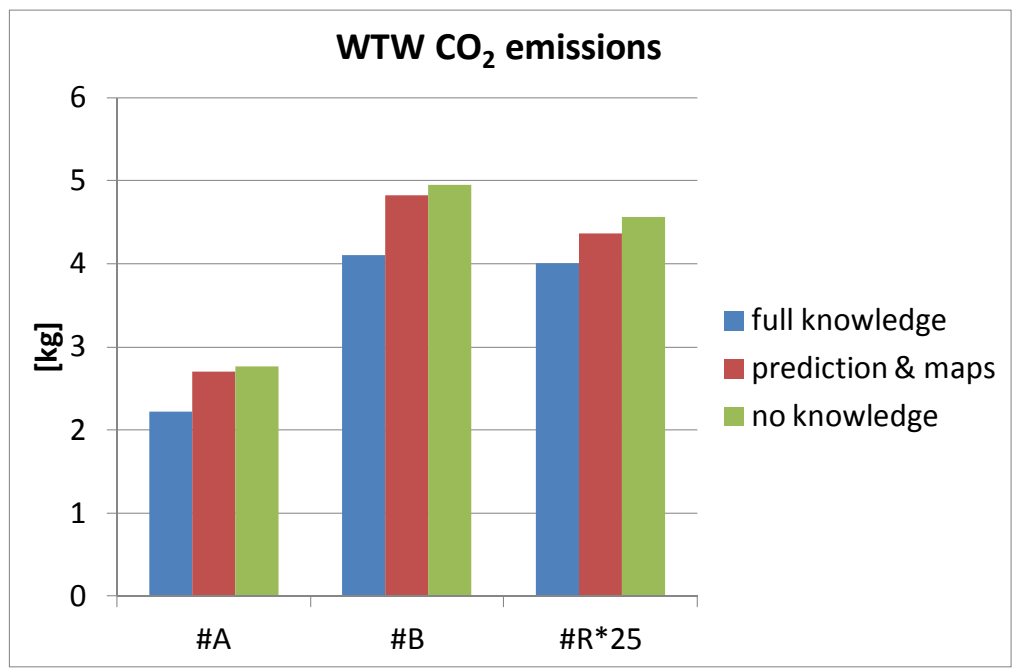

Figure 14. Well to wheel emissions of $\mathrm{CO}_{2}$ for the proposed approaches

The results of the predictionEmaps approach are intermediate between full-knowledge and noknowledge cases. Nevertheless, the results in terms of $\mathrm{CO}_{2}$ are not satisfactory since the proposed approach helps to reduce the greenhouse emission by only $2-4 \%$. This results suggest the possibility to replace or integrate the goal of the optimization process (eq. 1) with a cost function that takes into account the overall well-to-wheel emission of $\mathrm{CO}_{2}$. Moreover, better results could be obtained by increasing the duration of the prediction horizon.

\section{Summary and conclusions}

The chapter describes the optimal usage of an internal combustion engine in an intelligent hybrid electric vehicle able to sense its surrounding and adapt the energy management strategy to the actual driving conditions. After an introduction on hybrid electric vehicles and their challenges, the chapter describes the role of Information and Communication Technologies in the reduction of greenhouse emissions. Then, the chapter focuses on different approaches 
presented in literature on the usage of information about traffic and weather conditions for the optimal energy management of hybrid electric vehicles. In particular, the chapter describes the application of the predictionsmaps approach developed at the University of Salento for the optimization of the engine usage in the ITAN500 plug-in hybrid electric vehicle.

Finally, the chapter proposes four metrics to evaluate the performance of the proposed method: the percentage of mission performed before reaching the lowest allowed value for battery state of charge $(\mathrm{CBD} \%)$, the percentage of mission execute with the engine turned $\mathrm{ON}(\mathrm{EngON} \%$ ), the average efficiency of the engine (AEE), calculated according to its actual temperature and the overall well-to-wheel emissions of $\mathrm{CO}_{2}$.

\section{Author details}

Teresa Donateo

University of Salento, Italy

\section{Acknowledgement}

The investigation was supported by the University of Salento and the Italian Ministry for Environment (MATTM), through the funding of the "P.R.I.M.E." project.

\section{List of acronyms}

$\begin{array}{ll}\text { AEE } & \text { All Electric Range } \\ \text { BEV } & \text { Battery Electric Vehicles } \\ \text { CBD\% } & \text { \% of mission with controlled battery discharge } \\ \text { CD } & \text { Charge Depleting } \\ \text { CS } & \text { Charge Sustaining } \\ \text { ECMS } & \text { Equivalent Consumption Minimization Strategy } \\ \text { EngON\% } & \text { \% of mission with engine turned on } \\ \text { FCV } & \text { Fuel-Cell Vehicles } \\ \text { GPS } & \text { Global Positioning System } \\ \text { HEV } & \text { Hybrid Electric Vehicles } \\ \text { PHEV } & \text { Plug-in Hybrid Electric Vehicles } \\ \text { ICE } & \text { Internal Combustion Engine } \\ \text { SOC } & \text { State of Charge } \\ \text { TTW } & \text { Tank-to-Wheel } \\ \text { WTT } & \text { Well-to-Tank } \\ \text { WTW } & \text { Well-to-Wheel }\end{array}$

\section{References}

Anatone M., Cipollone R., Sciarretta A. (2011), “Control-Oriented Modeling and Fuel Optimal control of a Series Hybrid Bus", SAE paper 2005-01-1163. 
Barsali S., Miulli C., Possenti A. (2004), “A Control Strategy to Minimize Fuel Consumption of Series Hybrid Electric Vehicles", IEEE Transactions of Energy Conversion, Vol. 19, no. 1, pp. 187-195.

Bayar K., Bezaire B., Cooley B., Kruckenberg J., Schacht E., Midlam-Mohler S., and Rizzoni G. (2010), "Design of an extended-range electric vehicle for the EcoCAR challenge," ASME Conference Proceedings, vol. 2010, no. 44090, pp. 687-700.

Chan C.C. (2007), "The state of the Art of Electric, Hybrid, and Fuel Cell Vehicles", Proceeding of the IEEE, Vol. 95, No.4.

Ciccarese G., Donateo T., Palazzo C. (2012 in printing), “On-Board Prediction of Future Driving Profile for the Sustainable Mobility", Int. J. Automotive Technology and Management, Vol. x, No. x, ISSN (Online): 1741-5012 - ISSN (Print): 1470-9511.

Ciccarese G., Donateo T.,Marra P., Pacella D., Palazzo C. (2010), “On the Use of Vehicular Communications for Efficient Energy Management of Hybrid Electric Vehicles, Proceeding of Fisita 2010, Paper n. F2010E047.

Dimitrakopoulos G. (2011), "Intelligent Transportation Systems based on InternetConnected Vehicles: Fundamental Research Areas and Challenges", 11 ${ }^{\text {th }}$ International Conference on ITS Telecommunications.

Donateo T., Pacella D. (2012), "Modeling the Thermal Behavior of Internal Combustion in Hybrid Electric Vehicles with and without Exhaust Gas Heat Recirculation", Proceedings of the ASME 2012 Internal Combustion Engine Division Spring Technical Conference, May 6-9, 2012.

Donateo T., Pacella D., Laforgia D. (2011), “Development of an Energy Management Strategy for Plug-in Series Hybrid Electric Vehicle Based on the Prediction of the Future Driving Cycles by ICT Technologies and Optimized Maps", SAE Technical Paper 2011-01-0892.

Ericsson E. (2001), "Independent driving pattern factors and their influence on fuel-use and exhaust emission factors", Trans. Res., Part D, vol. 6, no. 5, pp. 325-341.

Ericsson E. (2000), “Variability in urban driving patterns”, Trans. Res., Part D, vol. 5, no. 5, pp. 337-354.

German J.M. (2003), Hybrid Powered Vehicles, SAE International, ISBN 0-7680-1310-0.

Gonder J. and Markel T. (2007), “Energy Management Strategies for Plug-In Hybrid Electric Vehicles", SAE Technical paper 2007-01-0290.

Gong Q., Tulpule P., Marano V., Midlam-Mohler S., Rizzoni G. (2011), “The role of ITS in PHEV Performance Improvement", American Control Conference ACC.

Gong Q., Li Y., Peng R. (2007), “Optimal Power Management of plug-in HEV with intelligent transportation systems", IEEE/ASME International Conference on Advanced Intelligent Mechantronics.

Gusikhin O., Filev D., Rychtyckyj N. (2008), “Intelligent Vehicle Systems: Applications and New Trends", Lecture Notes in Electrical Engineering, Volume 15, Part 1, 3-14.

Guzzella L., Onder C.H. (2004), Introduction to Modeling and Control of Internal Combustion Engine Systems, Springer Verlag, ISBN 354022274X, 2nd edition.

Guzzella L., Sciarretta, A. (2007), Vehicle Propulsion Systems, Introduction to Modelling and Optimization, Springer Verlag, ISBN 3540746919, 2nd edition.

International Energy Agency (2011), “CO2 Emissions from Fuel Combustion - 2011 Report".

Janota A., Dado M., Spalek J. (2010), “Greening Dimension of Intelligent Transport”, Journal of Green Energy, Vol 1-1 
Karbowski D., Rousseau A., Pagerit S., Sharer P. (2006), “Plug-in Vehicle Control Strategy: from Global Optimization to real-time application", 22 ${ }^{\text {nd }}$ Electric Vehicle Symposium, EVS22, Yokohama, Japan.

Lee J., Ohn H., Choi J-Y., Kim S. J., Min B. (2011) "Development of Effective Exhaust Gas Heat Recovery System for a Hybrid Electric Vehicle", SAE Technical Paper 2011-01-1171;

Lin C.-C, Peng H., Grizzle J. W., and Kang J.-M. (2003), “Power management strategy for a parallel hybrid electric truck", IEEE Trans. Control Syst. Technol., vol. 11, no. 6, pp. 839-849.

Markel T., Kuss M., Denholm P. (2009), “Communication and Control of Electric Drive Vehicles Supporting Renewables", Vehicle Power and Propulsion Conference, 2009. VPPC '09. IEEE.

Millo F., Rolando L., Servetto E. (2011), “Development of a Control Strategy for Complex Light-Duty Diesel-Hybrid Powertrains", SAE Technical paper 2011-24-0076.

Paladini V., Donateo T., de Risi A., Laforgia D. (2007), "Super-capacitors fuel-cell hybrid electric vehicle optimization and control strategy development", Energy Conversion and Management, 48 (11), p.3001-3008, ISSN: 0196-8904.

Schuricht P., Cassebaum O., Luft M., Baker B. (2010), "Methods and Algorithms in Control of Hybrid Powertraines, International congress of heavy vehicles, road trains and urban transport, 06-09 October 2010.

Sciarretta A., Guzzella L., and Back M. (2004), “A real-time optimal control strategy for parallel hybrid vehicles with on-board estimation of the control parameters," in Proc. IFAC Symp. Adv. Autom. Control, Salerno, Italy, April 19-23, 2004.

Serrao L, "A Comparative Analysis of Energy Management Strategies for Hybrid Electric Vehicles" (2009), Ph.D. Dissertation, The Ohio State University.

Serrao L., Rizzoni G. (2008), “Optimal Control of Power Split for a Hybrid Electric Refuse Vehicle", Proceedings of the 2008 American Control Conference.

Simpson A. (2006), "Cost-benefit Analysis of Plug-In Hybrid Electric Vehicle Technology", 22nd International Battery, Hybrid and Fuel Cell Electric Vehicle Symposium and Exhibition, 23- 28 October,Yokohama, Japan;

Sullivan, J.L., Baker, R.E., Boyer B.A., Hammerle R.H., Kenney T.E., Muniz L., Wallington T.J. (2004), " $\mathrm{CO}_{2}$ Emission Benefit of Diesel (versus Gasoline) Powered Vehicles", Environmental Science \& Technology, Vol. 38 No. 12.

Tulpule P., Marano V., Rizzoni G. (2009), “Effects of Different PHEV Control Strategy on Vehicle Perfomance", American Control Conference DSCC 2009.

Tulpule, P., Marano, V., and Rizzoni, G. (2011), "Effect of Traffic, Road and Weather Information on PHEV Energy Management," SAE Technical Paper 2011-24-0162.

Weng Y., Wu T. (2011), "Car-following model of vehicular traffic", International Conferences on Info-tech and Info-net 2001, ICII 2001, Oct. 2001.

Won J.-S. and Langari R. (2005), “Intelligent energy management agent for a parallel hybrid vehicle-Part 2: Torque distribution, charge sustenance strategies, and performance results", IEEE Trans. Veh. Technol., vol. 54, no. 3, pp. 935-953.

Yu S., Li L., Dong G. and Zhang X. (2006), "A Study of Control Strategies of PFI Engine during Cranking and Start for HEVs, Proceedings of IEEE International Conference on Vehicular Electronics and Safety, ICVES 2006.

Zuurendonk, B. (2005), Advanced Fuel Consumption and Emission Modeling using Willans line scaling techniques for engines", traineeship report, DCT 2005.116, Technische Universiteit Eindhoven. 